\title{
Evaluation of Empirical Antibiotic Therapy for the Treatment of Community-Acquired Urinary Tract Infections (CA-UTI)
}

\author{
João Pedro Aguiar*, Filipa Alves da Costa and Patrícia Cavaco Silva \\ Centro de Investigação Interdisciplinar Egas Moniz (CIIEM), Instituto Superior de Ciências da Saúde Egas Moniz, \\ Portugal
}

*Corresponding author: João Pedro Aguiar, Centro de Investigação Interdisciplinar Egas Moniz (CiiEM), Instituto Superior de Ciências da Saúde Egas Moniz, Rua D. Mafalda $n^{\circ} 371^{\circ} E S Q$, 2605-657 Belas, Lisboa, Portugal, Tel: +351-96 91041 37, E-mail: a.joao17@gmail.com

\begin{abstract}
Objectives: To characterize the pattern of indication of antibiotic regimens for CA-UTI; to evaluate the adequacy of antibiotic empirical therapy in CA-UTI and the resistance profile of the bacterial isolates.

Methods: An observational study was conducted, where the prevalence and resistance profiles of the microorganisms involved and the pattern of antibiotic indication were investigated through a cross-sectional approach. Patients presenting with UTI symptomatology and antibiotic indication were recruited through pharmacies in the Lisbon area. Upon inclusion, participants collected a urine sample and responded to a questionnaire characterizing the indication pattern and symptomatology presented. Samples were referred to a microbiology laboratory for urinalysis and antimicrobial susceptibility tests were performed according to EUCAST. Data were analyzed using IBM SPSS v20.0.
\end{abstract}

Results: A sample of 33 patients was obtained. Given the indicated therapy, $55.2 \%(n=6)$ corresponded to first line therapy and $10.3 \%$ to fluoroquinolones. It was also found that $6(22.2 \%)$ patients were treated with antibiotics and had no confirmed UTI. The most isolated microorganism was $E$. coli $(84.2 \%)$, followed by $P$. mirabilis $(5.3 \%), P$. aeruginosa $(5.3 \%)$ and Klebsiella sp. (5.3\%). Finally, a low resistance to first-line therapy and quinolones was observed, whilst high resistance was found to amoxicillin clavulanate $(n=10$; $52.6 \%)$.

Conclusion: This study revealed that most patients with UTI used nitrofurantoin and fosfomycin empirically (both included in first line therapy), and only a small number used quinolones. As expected, the most commonly isolated microorganism was $E$. coli. A worrisome finding was that nearly a quarter of patients were prescribed antibiotics without indication.

\section{Keywords}

Urinary tract infection, Antibacterial drug resistance, Fluoroquinolones

\section{Introduction}

Urinary Tract Infection (UTI) is one of the most common type of community and hospital acquired infections. Additionally, in the community, UTI is responsible for the majority of antibiotic prescription [1,2].

Antibiotic therapy is normally empirical, for in most cases urinalysis is not recommended, and, in the cases where it is performed the results of antibiotic susceptibility tests (AST) arrive after the beginning of therapy [3]. Thereby, there are several national guidelines for non-complicated UTI (e.g. Infarmed, Ordem dos Farmacêuticos - OF-and Direção Geral de Saúde - DGS) that were created based on the etiology of this type of infection and the respective resistance pattern [1,4-6]. In this study the DGS guideline was used, for it is issued by the national health authorities. This guideline recommends as first-line therapy: fosfomycin $(3000 \mathrm{mg} / 1$ day) and nitrofurantoin (100mg, 6/6h per 5-7 days); and as second-line therapy: amoxicillin clavulanate $(500+125 \mathrm{mg}, 8 / 8 \mathrm{~h}$ per 5-7 days) [4].

Nowadays, antibiotic resistance is a major public health concern. Fluoroquinolones normally are not included in first line UTI therapies, however they are often used in uncomplicated UTI and considered as an alternative therapy [7]. Portugal is one of the European countries with the highest rate of fluoroquinolones consumption (3.5 DDD/1.000 inhabitants/day), having ciprofloxacin as the most prescribed drug [8]. The resistance to this therapeutic class ranges from $2.2 \%$ to $69 \%$ for strains isolated from patients with uncomplicated CA-UTI and, according to the Antimicrobial Resistance Epidemiological Survey on Cystitis (ARESC) study, $5.8 \%$ of uropathogenic E. coli were resistant to fluoroquinolones, in Portugal [7].

Currently, the existing studies are based on the results of the urinalysis performed in clinical analysis laboratories, to determine the distribution of microorganisms commonly involved in this kind of infection and its resistance profile. However, these kind of studies do not succeed in the characterization of the indication pattern and utilization profile of the antibiotic therapy prescribed for UTI, due to lack of access to this type of data.

The main goals of this study were to characterize the pattern of indication of antibiotic regimens used in CA-UTI; to evaluate the adequacy of antibiotic empirical therapy in CA-UTI and the resistance profile of the bacterial isolates. Furthermore, three research questions and their respective hypotheses were formulated:

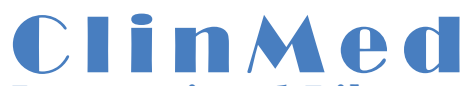

International Library

Citation: Aguiar JP, da Costa FA, Silva PC (2015) Evaluation of Empirical Antibiotic Therapy for the Treatment of Community-Acquired Urinary Tract Infections (CA-UTI). Int Arch Clin Pharmacol 1:002

Received: April 22, 2015: Accepted: July 25, 2015: Published: July 28, 2015

Copyright: ( 2015 Aguiar JP. This is an open-access article distributed under the terms of the Creative Commons Attribution License, which permits unrestricted use, distribution, and reproduction in any medium, provided the original author and source are credited. 
Question 1: Are recurrent UTIs ${ }^{1}$ [9] less associated with an adequate indication?

$\mathrm{H}_{0}$ : The recurrent UTI are not associated with a less adequate indication.

$\mathrm{H}_{1}$ : The recurrent UTI are associated with a less adequate indication.

Question 2: Is empirical therapy adequate to treat existing UTI?

$\mathrm{H}_{0}$ : The empirical therapy in not adequate to the existence of UTI.

$\mathrm{H}_{1}$ : The empirical therapy is adequate to the existence of UTI.

Question 3: Is the indication of quinolones related with the resistance to this therapeutic class?

$\mathrm{H}_{0}$ : Indication of quinolone is not related with the resistance to this therapeutic class.

$\mathrm{H}_{1}$ : Indication of quinolone is related with the resistance to this therapeutic class.

\section{Methods}

\section{Study design}

A cross-sectional study was used to provide information about the distribution of microorganisms commonly involved in CA-UTI, as well as their resistance profile. This type of study, being carried out in the community pharmacy, in one single moment of time, also allows for the characterization of the established antibiotic regimens performed by patients.

\section{Population and sample}

Population: The population used in this study consisted of patients with CA-UTI who resorted to community pharmacies in the Lisbon area, from December of 2012 to March of 2013.

Eighty-two pharmacies were invited to participate in the study and were selected according to the districts that were nearest the ISCSEM and the researcher's house that made the sample collection. However only 10 actively recruited patients. The theoretical population was estimated based on sales data of antibiotics exclusively used for this type of infection (fosfomycin and nitrofurantoin). These data were provided by the participating pharmacies and indicated that one should expect to find 690 patients presenting at these pharmacies seeking these medicines for UTIs, considering the three months for patient recruitment. Assuming that only $10 \%$ of the patients would be willing to participate, given the complexity of the study procedures, the final population would be 69 patients.

Eligibility criteria: Defined inclusion criteria were:

a) Patients with UTI who presented with typical symptomatology and/or requested drugs, with/without prescription, for UTI and for personal use;

b) Patients that during the time of study resorted to participating pharmacies;

c) Patients who agreed to participate in the study.

Exclusion criteria were:

a) Patients institutionalized either in hospitals or in nursing homes;

b) Patients unable to communicate in Portuguese, either by language barriers or by apparent mental incapacity.

\section{Data collection}

Questionnaire: Eligible patients were invited to participate in the study and to answer a questionnaire. The data collection tool consisted of nine questions comprising sociodemographic characterization of the sample and characterization of the parameters relative to the ${ }^{1}$ Recurrent UTI is described as the presence of at least three episodes in the last twelve months. diagnosis (e.g. symptomatology, previous urinalysis, presence of recurrent UTI and information about UTI recurrence) and therapy (e.g. drug indicated and by whom; dosage indicated and by whom; treatment duration indicated and by whom).

After answering the questionnaire and before initiating antibiotic therapy, patients collected an urine sample according to the clean catch mid-stream technique and kept it at $4^{\circ} \mathrm{C}$ in the pharmacy, till the research team went to collect it (maximum 24 hours).

Urinalysis: Urine samples were referred to the microbiology laboratory of ISCSEM and UTI were confirmed by: direct examination of urine sediment; bacteriuria quantification; and identification of bacterial isolates. Bacteriuria was estimated by CLED agar (Oxoid, Basingstoke, UK) inoculation by the calibrated-loop technique, and bacterial isolates were identified using a chromogenic agar - ChromID CPS agar (bioMérieux, Lyon, France).

Results of urinalysis were reported as:

- Presence of UTI - significant leukocyturia and, bacteriuria(equal or greater than $10^{5} \mathrm{CFU} / \mathrm{ml}$ ) and pure culture of the microorganism;

- Inconclusive - observation of epithelial cells, low bacteriuria and/or presence of mixed flora;

- Absence of UTI - non significant leukocyturia and bacteriuria (equal or less than $10^{2} \mathrm{CFU} / \mathrm{ml}$ ).

Antimicrobial susceptibility tests: Antimicrobial Susceptibility Tests (AST) was performed using the disk diffusion test (KirbyBauer test) according to European Committee on Antimicrobial Susceptibility Testing (EUCAST) recommendations. The following antibiotics disks were used: (Oxoid, Basingstoke, UK): amoxicillin $(10 \mu \mathrm{g})$, amoxicillin clavulanate $(20+10 \mu \mathrm{g})$, cefotaxime $(30 \mu \mathrm{g})$, cefuroxime $(30 \mu \mathrm{g})$, gentamicin $(10 \mu \mathrm{g})$, nitrofurantoin $(300 \mu \mathrm{g})$, cotrimoxazole $(23.75+1.25 \mu \mathrm{g})$, ciprofloxacin $(5 \mu \mathrm{g})$, norfloxacin $(10 \mu \mathrm{g})$, fosfomycin $(50 \mu \mathrm{g})$ and aztreonam $(30 \mu \mathrm{g})$. The results were reported as sensitive, intermediate or resistant, according to EUCAST criteria.

\section{Data analysis}

Data analysis was performed using the software IBM SPSS version 20.0. Descriptive analysis of categorical and scalar variables was performed. Furthermore, bivariate statistics were used to answer the established hypotheses, resorting to non-parametric tests, namely chi-square test and Fischer's exact test. For all tests, a confidence interval of $95 \%$ was considered.

\section{Results}

\section{Real sample}

From the 82 invited pharmacies, 20 agreed to participate but only 10 pharmacies actively recruited patients. Thus, the real adherence rate of pharmacies was $12.20 \%$. The patient sample recruited was 33 individuals, corresponding to a recruitment rate of $47.8 \%$.

\section{Sociodemographic characterization}

The sociodemographic characterization was performed using three parameters: age, gender and education level. The majority of patients were female $(\mathrm{n}=31 ; 93.9 \%)$, with a mean age of 51 years $(\mathrm{SD}=$ 18.048), ranging from 21 to 81 years old. Most patients had only basic education $(n=10 ; 32.3 \%)$, followed by high school education $(n=6$; $27.3 \%)$ and first cycle of higher education $(n=4 ; 18.2 \%)$. Post-high school education and second cycle of higher education were the less frequent with $4.5 \%(\mathrm{n}=1)$ for both.

\section{Characterization of indication pattern for CA-UTI}

Diagnosis: The diagnosis of UTI was based on the symptomatology described by patients and the results of the urinalysis. Thus, $57.6 \%$ $(n=19)$ of patients presented a positive result for UTI, 27.3\% $(n=9)$ had a negative result and a few had an inconclusive result $(n=5$; $15.2 \%)$. The urinalysis results are described in figure 1. 


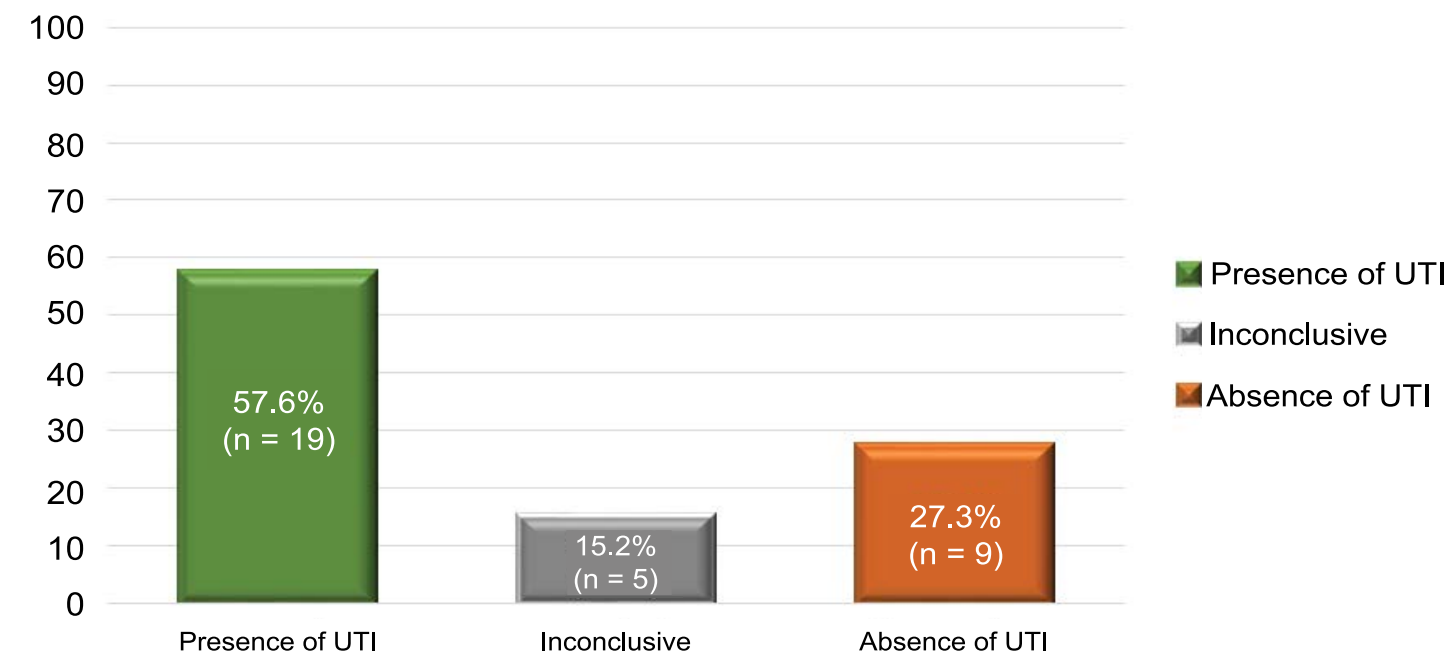

Figure 1: Urinalysis results

Table 1: DGS guidelines: therapeutic recommendations for uncomplicated UTIs.

\begin{tabular}{|c|c|c|c|}
\hline Therapy & Drug & Dosage/posology & Treatment Duration \\
\hline \multirow{2}{*}{ First-line therapy } & Fosfomycin & $\begin{array}{c}3000 \mathrm{mg} \\
24 / 24 \text { hours }\end{array}$ & 1 day \\
\hline & Nitrofurantoin & $\begin{array}{c}100 \mathrm{mg} \\
6 / 6 \text { hours }\end{array}$ & 5-7 days \\
\hline Second-line therapy & Amoxicillin/clavulanate & $\begin{array}{c}625 \mathrm{mg}(500+125 \mathrm{mg}) \\
8 / 8 \text { hours }\end{array}$ & 5-7 days \\
\hline
\end{tabular}

Table 2: Distribution of indicated therapy

\begin{tabular}{|c|c|c|c|c|c|}
\hline \multirow{2}{*}{ Therapy } & \multirow{2}{*}{ Drug } & \multicolumn{3}{|c|}{ Indication } & \multirow{2}{*}{ Total } \\
\hline & & Physician & Pharmacist & Patient & \\
\hline \multirow{2}{*}{ First-line therapy } & Fosfomycin & $\begin{array}{c}24.15 \% \\
(n=7)\end{array}$ & $\begin{array}{c}3.45 \% \\
(n=1)\end{array}$ & $\begin{array}{l}6.9 \% \\
(n=2)\end{array}$ & \multirow{2}{*}{$\begin{array}{l}55.2 \% \\
(n=16)\end{array}$} \\
\hline & Nitrofurantoin & $\begin{array}{c}13.8 \% \\
(n=4)\end{array}$ & $\begin{array}{c}3.45 \% \\
(n=1)\end{array}$ & $\begin{array}{c}3.45 \% \\
(n=1)\end{array}$ & \\
\hline Second-line therapy & Amoxicillin clavulanate & $\begin{array}{l}6.9 \% \\
(n=2)\end{array}$ & $\begin{array}{l}0.0 \% \\
(n=0)\end{array}$ & $\begin{array}{l}0.0 \% \\
(n=0)\end{array}$ & $\begin{array}{l}6.9 \% \\
(n=2)\end{array}$ \\
\hline Fluoroquinolones & Norfloxacin & $\begin{array}{c}10.3 \% \\
(n=3)\end{array}$ & $\begin{array}{l}0.0 \% \\
(n=0)\end{array}$ & $\begin{array}{l}0.0 \% \\
(n=0)\end{array}$ & $\begin{array}{c}10.3 \% \\
(n=3)\end{array}$ \\
\hline Others Antibiotics & Co-trimoxazole & $\begin{array}{l}6.9 \% \\
(n=2)\end{array}$ & $\begin{array}{l}0.0 \% \\
(n=0)\end{array}$ & $\begin{array}{l}0.0 \% \\
(n=0)\end{array}$ & $\begin{array}{l}6.9 \% \\
(n=2)\end{array}$ \\
\hline \multirow{3}{*}{ Others Therapies } & Flavoxate & $\begin{array}{c}3.45 \% \\
(n=1)\end{array}$ & $\begin{array}{c}10.35 \% \\
(n=3)\end{array}$ & $\begin{array}{l}0.0 \% \\
(n=0)\end{array}$ & \multirow{3}{*}{$\begin{array}{c}20.7 \% \\
(n=6)\end{array}$} \\
\hline & Trospium chloride & $\begin{array}{c}3.45 \% \\
(n=1)\end{array}$ & $\begin{array}{l}0.0 \% \\
(n=0)\end{array}$ & $\begin{array}{l}0.0 \% \\
(n=0)\end{array}$ & \\
\hline & Cranberry & $\begin{array}{l}0.0 \% \\
(n=0)\end{array}$ & $\begin{array}{c}3.45 \% \\
(n=1)\end{array}$ & $\begin{array}{l}0.0 \% \\
(n=0)\end{array}$ & \\
\hline
\end{tabular}

The recurrence profile of UTI revealed that four female patients (13.3\%) were in presence of a recurrent UTI and the average of these episodes in the precedent year was $3.78(\mathrm{SD}=1.856)$, ranging from 3 to 7 episodes.

Therapy: From the 33 patients analyzed, four did not have an indication for antibiotic therapy as no bacteria were detected in the urinalysis. Therapy was prescribed by physicians in the majority of cases $(n=20 ; 69.0 \%)$ and in $31.0 \%(n=9)$ it was dispensed without a prescription. In the latter case, $66.67 \%(n=6)$ of the indicated therapy was counseled by the pharmacist and the remaining $33.33 \%(n=3)$, was sought by patients.

More than half of the indicated antibiotics ( $\mathrm{n}=16 ; 55.2 \%)$ were first-line therapy and only $10.3 \%(n=3)$ corresponded to fluoroquinolones. Second-line therapy was less frequently found $(\mathrm{n}=2 ; 6.9 \%)$, as well as other antibiotics such as co-trimoxazole $(\mathrm{n}=2$; $6.9 \%)$. In some situations, adjuvant therapy was indicated $(n=6$; 20.7\%), including flavoxate, trospium chloride and cranberry based products. Results are described in more detail in table 2.
Dosage and treatment duration were also evaluated. It was found that physicians were responsible for the majority of therapeutic regimens, with $73.1 \%(\mathrm{n}=19)$ for dosage and $81.8 \%(\mathrm{n}=18)$ for treatment duration. The remaining regimens correspond to pharmaceutical indication. Table 3 summarizes the dosage/posology and duration treatment most indicated by these two healthcare professionals.

Association between UTI recurrence and indication pattern: The study intended to evaluate if there was a relationship between the recurrence profile and a less appropriate indication. Results indicate that recurrent UTIs are most frequently treated with firstline therapy than with second line (Table 4). However, this trend did not reveal statistical significance. Therefore, one must conclude that in this study there was no relation between the two variables, i.e., the utilization of first or second-line therapy instead of other antibiotic therapies, occurs independently of recurrence of UTI $(p=0.765)$.

\section{Evaluation of the need of antibiotic therapy for CA-UTI}

One could assume that only patients presenting a UTI would 
Table 3: Distribution of indications provided by health care professionals regarding dosage, posology and duration of treatment

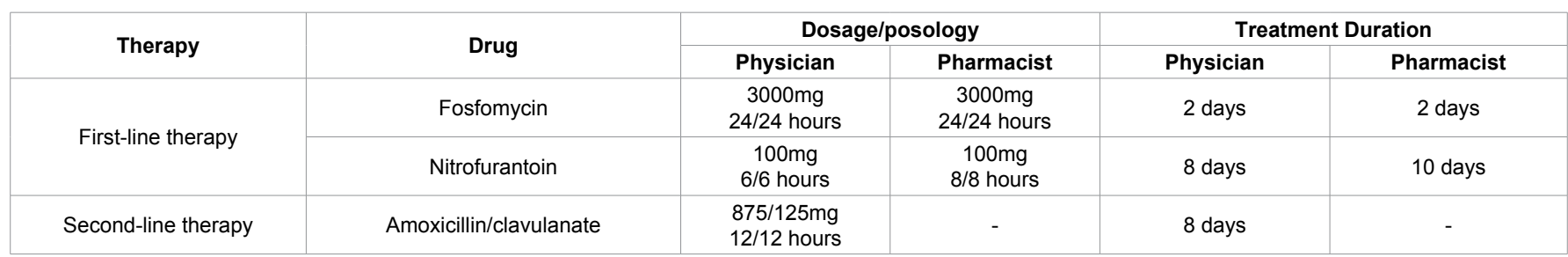

Table 4: Association between UTI recurrence and indication pattern

\begin{tabular}{|c|c|c|c|c|}
\hline \multirow{2}{*}{ Indicated therapy } & \multicolumn{2}{|c|}{ UTI } & \multirow{2}{*}{ Total } & \multirow{2}{*}{$p$} \\
\hline & Recurrent & Non-recurrent & & \\
\hline First-line therapy & $\begin{array}{c}4 \\
(25.0 \%)\end{array}$ & $\begin{array}{c}12 \\
(75.0 \%)\end{array}$ & $\begin{array}{c}16 \\
(100.0 \%)\end{array}$ & \multirow{3}{*}{0.765} \\
\hline Second-line therapy & $\begin{array}{c}0 \\
(0.0 \%)\end{array}$ & $\begin{array}{c}1 \\
(100.0 \%)\end{array}$ & $\begin{array}{c}17 \\
(100.0 \%)\end{array}$ & \\
\hline Total & $\begin{array}{c}4 \\
(23.5 \%)\end{array}$ & $\begin{array}{c}13 \\
(76.5 \%)\end{array}$ & $\begin{array}{c}17 \\
(100.0 \%)\end{array}$ & \\
\hline
\end{tabular}

Table 5: Association between antibiotic therapy and existence of UTI

\begin{tabular}{|c|c|c|c|c|}
\hline \multirow{2}{*}{ Indication of antibiotic therapy } & \multicolumn{2}{|c|}{ Presence of UTI } & \multirow{2}{*}{ Total } & \multirow{2}{*}{$p$} \\
\hline & Yes & No & & \\
\hline Yes & $\begin{array}{c}16 \\
(72.7 \%)\end{array}$ & $\begin{array}{c}6 \\
(27.3 \%)\end{array}$ & $\begin{array}{c}22 \\
(100.0 \%)\end{array}$ & \multirow{3}{*}{0.472} \\
\hline No & $\begin{array}{c}3 \\
(60.0 \%)\end{array}$ & $\begin{array}{c}2 \\
(40.0 \%)\end{array}$ & $\begin{array}{c}5 \\
(100.0 \%)\end{array}$ & \\
\hline Total & $\begin{array}{c}19 \\
(70.4 \%)\end{array}$ & $\begin{array}{c}8 \\
(29.6 \%)\end{array}$ & $\begin{array}{c}27 \\
(100.0 \%)\end{array}$ & \\
\hline
\end{tabular}

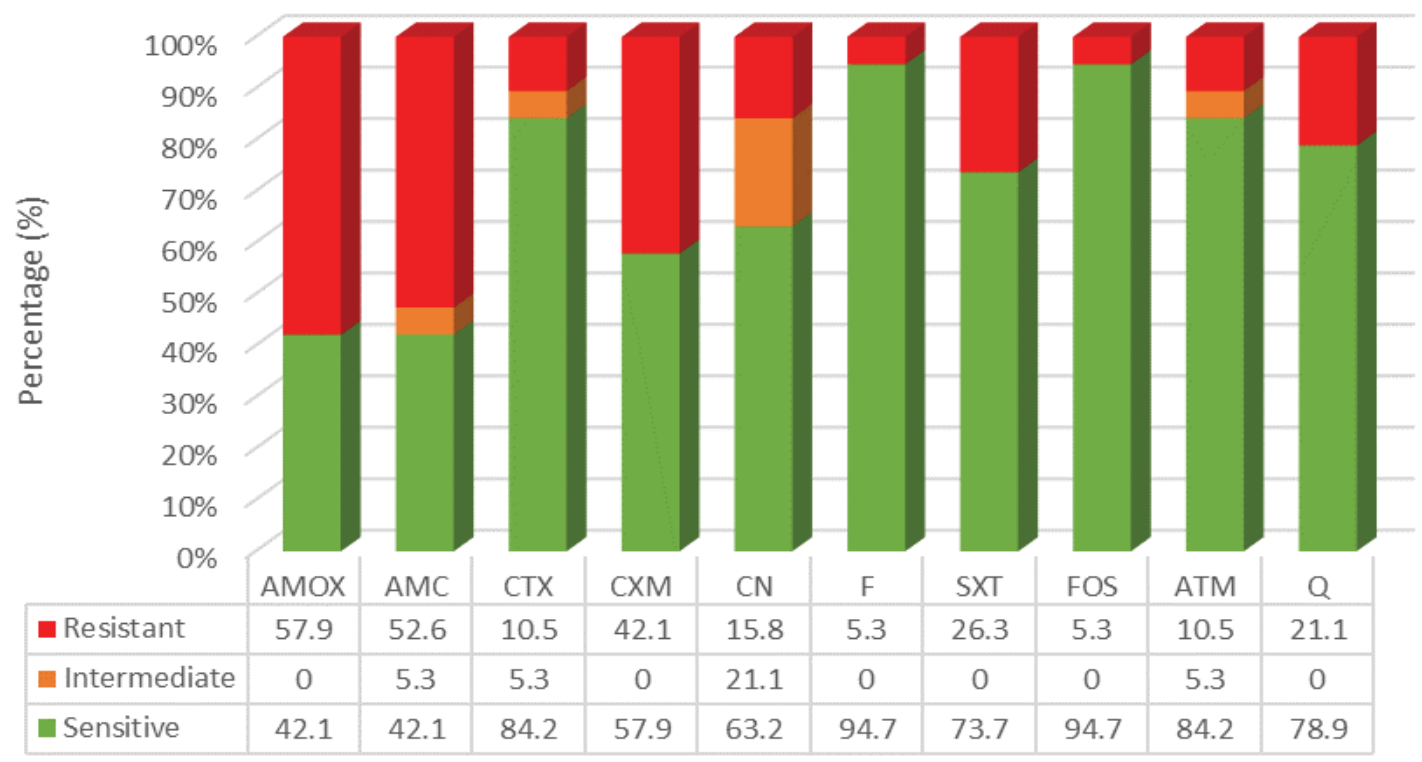

Figure 2: Antimicrobial susceptibility test - kirby-bauer method

AMOX: Amoxicillin, AMC: Amoxicillin Clavulanate, CTX: Cefotaxime, CXM: Cefuroxime, CN: Gentamicin, F: Nitrofurantoin, SXT: Co-trimoxazole, FOS: Fosfomycin, ATM: Aztreonam, Q: Fluoroquinolones

receive a prescription for antibiotic therapy. However, while data revealed that $59.3 \%$ of patients with UTI $(n=16)$ were indicated antibiotic therapy, $22.2 \%(n=6)$ that did not present a UTI also had an indication of antibiotic (Table 5), a trend not supported by statistical significance $(\mathrm{p}=0.4729)$.

\section{Evaluation of the adequacy of antibiotic therapy for CA-UTI}

The microorganism most commonly isolated was $E$. coli with $84.2 \%(\mathrm{n}=16)$ followed by Klebsiella sp. $(5.3 \% ; \mathrm{n}=1)$, Pseudomonas aeruginosa $(5.3 \% ; \mathrm{n}=1)$ and Proteus mirabilis $(5.3 \% ; \mathrm{n}=1)$.

Focusing on the susceptibility profile to first and second-line therapy, and also to fluoroquinolones, it was found that $94.7 \%(n=18)$ of bacterial isolates were sensitive to nitrofurantoin and fosfomycin. Relatively to fluoroquinolones (ciprofloxacin and norfloxacin), $78.9 \%(n=15)$ of bacterial isolates were sensitive and $21.1 \%(n=4)$ were resistant. These four bacterial isolates were all uropathogenic $E$. coli. An interesting finding was the high level of resistance obtained for amoxicillin/clavulanate, which was $52.6 \%(n=10)$. The results are described in figure 2.

Based on AST, it was estimated that $26.67 \%$ of patients $(n=4)$ were taking an antibiotic for which the microorganism was resistant. It was also intended to evaluate if the use of quinolones was related to an 
Table 6: Association between indication of quinolones and resistance to this therapeutic class

\begin{tabular}{|c|c|c|c|}
\hline \multirow{2}{*}{ Resistance to quinolones } & \multicolumn{2}{|c|}{ Indication of quinolones } & \multirow{2}{*}{ Total } \\
\cline { 2 - 4 } & Yes & No & 15 \\
\hline No & 2 & 13 & $(100.0 \%)$ \\
\hline Yes & $(13.3 \%)$ & $(86.7 \%)$ & 4 \\
\hline Total & 0 & 4 & $(100.0 \%)$ \\
\hline
\end{tabular}

increased resistance for this therapeutic class. Data indicates that all patients with resistance to this class did not use a quinolone (Table 6). However, the relationship was not statistically significant $(\mathrm{p}=0.614)$.

\section{Discussion}

The patient sample was primarily composed of females, mostly with basic education. These results are in line with what is established for UTI - that female patients have a higher probability of having an UTI in comparison with men [1]. Moreover, the educational level has been suggested to be an important factor that increases the possibility of suffering an UTI episode [10]. However, in the majority of cases a significant statistical relation between the two variables was not found. Thus, sample characteristics are superimposable with the ones of the population.

Normally, UTI are diagnosed solely based on the symptomatology described by patients. According to the literature, the best symptoms that can predict an UTI are urinary frequency and urgency, and dysuria, but should be confirmed with a laboratory test (e.g. urine dipsticks/sediment microscopic observation or urinalysis) whenever possible [11]. The results presented here show that symptomatology by itself is not a good indicator of the presence of UTI, and therefore it is useful to complement clinical evaluation with laboratory tests, for a correct management of UTI.

In most cases antibiotic therapy begins before results of AST are known [12], therefore, it is necessary to study if national guidelines are followed by healthcare professionals. It was found that about half the patients used the first-line therapy recommended by the DGS, which is a good indicator. However, an important and worrisome finding was that some patients were taking antibiotics and had a negative result in urinalysis, in other words they had no confirmed UTI. The use of unnecessary antibiotics is a well-established cause in the emergence of antibiotic resistance [13]. Additionally, comparing the dosage and treatment duration indicated in the DGS guidelines with the results presented in this study, it is possible to conclude that these were not coincident. It was found that the dosage and treatment duration indicated were higher than the established in the literature and this fact can contribute to an increase in antimicrobial resistance. Furthermore, the indications given by physicians are more approximated to the DGS guidelines when compared to those given by pharmacists, which suggests that pharmacists should engage more often in continuous professional development (CPD) if they intend to have an extended role in the management of UTI. Nevertheless, in some situations nitrofurantoin can be prescribed for UTI prophylaxis, and so, treatment duration can be longer than the 5-7 days indicated in the guideline.

The microorganism most isolated was E. coli and, according to the literature, this bacteria is found in $75-95 \%$ of uncomplicated cystitis [12]. It is also important to mention that in some cases the microorganism had already acquired resistance to the indicated antibiotic, which compromises the correct treatment of the UTI and may increase the risk of suffering a recurrent episode in the future. This hypothesis was not supported by the reported data, most probably due to the reduced sample size, which makes bivariate analysis an unprofitable task.

A study conducted by Gupta and collaborators (2011) showed that antimicrobial resistance is normally higher in Portugal and Spain when compared to other European countries due to the higher consumption of antimicrobial drugs in these two countries [12]. Given the resistance profile, it was found that most of the bacterial isolates were sensitive to first-line therapy and fluoroquinolones. According to literature, it was expected to obtain high resistance to fluoroquinolones which has been one of the most prescribed drugs in the treatment of UTI [4,7]. However, in this study, a low resistance to this therapeutic class was found, probably due to the sample size, making the authors believe that the value could be underestimated. Interestingly, over half of the bacterial isolates presented resistance to second-line therapy - amoxicillin/clavulanate. This could eventually be related to the high consumption of this antibiotic in others types of infections: odontogenic and respiratory tract infections. Therefore, it is urgent to monitor the emergence of resistance in Portuguese uropathogenic isolates so that guidelines remain appropriate.

This study has several limitations worth discussing. First, the difficulty in implementing the project, attributable to the fact that the success of research was not only dependent on the work of the research team, but also in the active participation of pharmacies, who seem to be currently demotivated, probably due to the difficulties they are experiencing, in the context of the current crisis the pharmaceutical sector is going through in Portugal, which has led to a decreased interest and availability to participate in research studies. Major changes to be mentioned include medicines' price reduction in addition to reduced profit margins, reaching its peak in 2011, ultimately aggravated by the global financial crisis. These factors, conjugated, have been making the activity of some pharmacies untenable, leading in many cases to a decrease of the pharmaceutical team, which could bring as a consequence, the impossibility of participating in research studies [14]. Namely, it was very difficult to monitor the participating pharmacies, which were frequently difficult to reach, as they sometimes did not respond to the contacts, via e-mail or phone.

Secondly, the law forbids the urine sample collection in pharmacies, unless granted the status of collection centre, leading the team to develop an alternative plan to make the project feasible. As such, recruited patients collected the urine samples at their homes and the team collected it from there, a procedure one believes may have decreased the participation rate. The main limitation was unquestionably the sample size and therefore these results cannot be extrapolated. Moreover, this fact can be the main cause for the inability to demonstrate any of the relationships hypothesized.

Finally, it is important also to acknowledge the importance of this work, as most studies in this area focus, either on the prevalence of bacterial isolates, and are therefore conducted via clinical analysis laboratories, or on the prescription pattern, the latter having no access to microbiology information. This study aimed to evaluate these two aspects simultaneously, which obviously contributes to the added value of the undertaken work, but also adds complexity to its achievement, which is also another explanation for the low sample obtained.

It would be very useful to be able to implement this study in more pharmacies, as patients involved greatly valued the service provided, which they do not normally have access to. This project is currently under evaluation by national representative bodies, in order to evaluate its interest and feasibility in implementing it as a nationwide project. 


\section{Conclusions}

It was found that the majority of patients participating in this study used first-line therapy and very few had been prescribed second-line therapy; however, there were a considerable proportion of patients resorting to fluoroquinolones. The high resistance to second-line therapy was a worrying finding.

\section{Ethical Statement}

The study was approved by the Ethics Committee of the Instituto Superior de Ciências da Saúde Egas Moniz (ISCSEM) and was also notified and approved by the National Commission of Data Protection (Comissão Nacional de Proteção de Dados - CNPD).

Patients were informed about the study objectives and methodology proposed, both orally and written. Once agreeing to participate, patients signed an informed consent form. To preserve anonymity, alphanumeric codes were used to identify the patients.

\section{Acknowledgments}

The authors greatly thank the participating pharmacies, pharmacists and patients, for making this study possible. CRL

This work was supported by Egas Moniz- Cooperativa de Ensino Superior,

\section{References}

1. (2007) Susceptibilidade aos Antimicrobianos. Acta Médica Portuguesa 20 543-549.

2. Nicolle L, Anderson PA, Conly J, Mainprize TC, Meuser J, et al. (2006) Uncomplicated urinary tract infection in women. Current practice and the effect of antibiotic resistance on empiric treatment. Can Fam Physician 52 : 612-618

3. Linhares I, Raposo T, Rodrigues A Almeida A (2013) Frequency and antimicrobial resistance patterns of bacteria implicated in community urinary tract infections: a ten-year surveillance study (2000-2009). BMC infectious diseases 13: 19

4. Mehnert-Kay SA (2005) Diagnosis and management of uncomplicated urinary tract infections. American family physician 72: 451-456.

5. Kothari A, Sagar $\vee(2005)$ Antibiotic resistance in pathogens causing community-acquired urinary tract infections in India: a multicenter study. J Infect Dev Ctries 2: 354-358.
6. Bailey AM, Weant K a, Baker SN (2013) Prevalence and risk factor analysis of resistant Escherichia coli urinary tract infections in the emergency department. Pharmacy practice 11: 96-101.

7. Gupta K, Hooton T, Stamm W (2001) Increasing Antimicrobial Resistance and the Management of Uncomplicated Community-Acquired Urinary Tract Infections. American College of Physicians 135: 41-50.

8. Direção Geral de Saúde (DGS) (2011) Norma no015/2011: Terapêutica da infeção do aparelho urinário 1-10.

9. Infarmed (2011) Prontuário Terapêutico: Anti-infecciosos e anti-sépticos urinários. 10a Edição. 323-324.

10. Caramona M, Vitória I, Teixeira M, Alcobia A, Almeida P, et al. (2011) Normas de Orientação Terapêutica 70-79.

11. George F (2008) Histórias de Saúde Pública.

12. Dalhoff A (2012) Global fluoroquinolone resistance epidemiology and implictions for clinical use. Interdiscip Perspect Infect Dis 2012: 976273.

13. Oteo J, Campos J (2004) [Quinolone use and resistance]. Enferm Infecc Microbiol Clin 22: 201-203.

14. Direção Geral de Saúde (DGS) (2004) Plano Nacional de Saúde 2004/2010 - Orientações Estratégicas.

15. Rolo F, Parada B, Moreira P (2008) Cistite não complicada na mulher: Guia multidisciplinar reconhecido pela Associação Portuguesa de Urologia. Associação Portuguesa de Urologia 1-32.

16. Foxman B (2003) Epidemiology of urinary tract infections: incidence, morbidity, and economic costs. Dis Mon 49: 53-70.

17. Kardas P, Devine S, Golembesky A, Roberts C (2005) A systematic review and meta-analysis of misuse of antibiotic therapies in the community. Int $\mathrm{J}$ Antimicrob Agents 26: 106-113.

18. Mishra B, Srivastava S, Singh K, Pandey A, Agarwal J (2012) Symptombased diagnosis of urinary tract infection in women: are we over-prescribing antibiotics? Int J Clin Pract 66: 493-498.

19. Gupta K, Hooton TM, Naber KG, Wullt B, Colgan R, et al. (2011) International clinical practice guidelines for the treatment of acute uncomplicated cystitis and pyelonephritis in women: A 2010 update by the Infectious Diseases Society of America and the European Society for Microbiology and Infectious Diseases Clin Infect Dis 52: 103-120.

20. Marques F, Silva J (2012) A sustentabilidade das farmácias e o medo dos medicamentos caros 